\title{
Influence of linguistic factors on teaching and learning English at primary, secondary and tertiary educational levels
}

\author{
N. Orlova \\ Cherkasy National Bohdan Khmelnytsky University, Cherkasy, Ukraine \\ Corresponding author. E-mail: orlanvla@ukr.net
}

Paper received 07.08.18; Accepted for publication 18.08.18.

https://doi.org/10.31174/SEND-PP2018-173VI71-08

\begin{abstract}
Linguistic factors play a crucial role in planning, organising, teaching and learning English at primary, secondary and tertiary education levels. The article has analysed the key linguistic factors playing a significant part in the process of teaching and learning the English language. The aim of the article is to assess and systematise the underlying linguistic aspects that should be recognised and comprehended by teachers of English at all levels of education, with special attention paid to the concepts "errors" and "mistakes", the ways and approaches to working on and correcting them, as well as issues in their identification and description. The article has considered current views on types and categories of errors including their characteristics, the possible sources and origins of errors, and approaches towards feedback and error correction. It has been defined that errors and mistakes can be classified as overt and covert, global and local, phonological, lexical, grammar or discourse, and errors of adding, omitting, replace or the sequence of use. Moreover, the author has distinguished typical sources of errors that include their interlingual and intralingual origins, communicative and sociolinguistic context, psycholinguistic or cognitive strategies as well as multiple affective variables. Among various factors that influence error correction, the most significant aspect is the type of feedback students receive as a reaction to their errors or mistakes. In this concern, the author has drawn attention to certain approaches to teachers' attitudes to working on their students' errors and mistakes namely to correct or ignore, and in case of correction, whether to do this immediately or after a while. The article has provided further explanations concerning types of implicit responses and explicit correction. Finally, it is significant to state that in order to enhance English learning organisation, it is necessary to remember that presented classifications of errors and mistakes with the existing ways of working them out should be not viewed as prescriptive or overly comprehensive. They aim to assist teachers in improving classroom methodologies and teaching process enhancement as well asto promote students' learning success.
\end{abstract}

Keywords: overt errors, covert errors, interlingual interference, intralingual interference, implicit response, explicit feedback.

Introduction. Linguistic factors deal not only with a single sole target language as a system. They touch upon certain relationships between a student's native tongue and the foreign language that is being learnt. Linguistic aspects concerning analysis of the native language- foreign language relationships promote better understanding of objective rules and regulations of functioning of teaching and learning mechanisms and lead to a better choice of the most appropriate methodological systems, strategies and approaches. In the middle of the twentieth century, the first attempts were made to study existence and functioning of the two languages based on the comparison (or contrast). Gradually, comparative and contrasting data have become the underlying idea of the hypothesis of contrastive analysis. The hypothesis highlights the importance of the first (native) language in learning a foreign language. The key concepts of the contrastive analysis hypothesis are interference and transfer. The idea that in the context of language learning, linguistic phenomena common to both native and target languages can be relatively easy learnt with fewer errors in subsequent language use, whereas phenomena which have no equivalents can cause difficulties and errors. According to the theory, teaching and learning a foreign language should rely on the data of thorough analysis of both languages' linguistic systems, which covers the detected phenomena similar to both languages and distinct from each other. Moreover, development of methodological typology of linguistic aspects inherent in both languages that allows to predict difficulties and to establish a clear progression in foreign languages teaching and learning played a crucial part in that context.

Recent literature and studies review encompasses the works by diverse prominent British, Australian,
American educators, such as J.C. Richards and Th.S. Rodgers, S. Corder, P. Lennon, N. Stenson, J. Hendrickson, N. Spada and others, who have investigated the types of errors and mistakes, their role in the English language teaching and learning, and numerous aspects of current approaches to errors correction, and consequently, improvement of students' learning process. However, despite the existence of many studies concerning errors as crucial linguistic aspects influencing English learning, there is a relative lack of systematising works on the subject. Thus, it would be vital to make attempts to systematise types of errors and mistakes, current approaches towards ways of giving feedback.

The article aims to conduct a detailed analysis of the current approaches towards the types, forms and characteristics of errors and mistakes. The goal of the work is to describe mechanisms of the processes within the aspects significant for development of effective responding to any error, regarding the latest data, as well as to examine the recent research concerning means and tools of providing effective feedback in order to create a favourable atmosphere for successful learning.

Materials and Methods. To achieve the objective set, the subsequent methods have been applied theoretical methods of analysing scientific and methodological literature on the topic under research; modelling and development of the methodological system and its educational and methodological implementation; theoretical generalisation, system approach, comparison and systematisation.

Results and Discussion. Interference or in other words, intervention of the native language, is stated to be the main impediment to successful foreign language learning. Interference as interaction of language systems that occurs during language learning contributes to invol- 
untary spontaneous transfer or overlapping of features of one language system onto the other language system. According to linguistics, interference appears as a result of the contact of two languages systems and may be noticeable at all language levels. Thus, we can speak about phonetic, grammatical, and lexical interference. Examples of phonetic interference include placing stress on the wrong syllable that has been transferred from the native language. For example, hOtel instead of hotEl, pronunciation of certain sounds in accordance to the norms of the native tongue as in the word xylophone the first letter is pronounced like $/ \mathbf{k s} /$ instead of $/ \mathbf{z} /$, erroneous pronunciation of so-called silent consonants in words like hour, knee, castle, climb, typical issues in pronouncing pure English sounds /ठ/ /0/ in words mother and father. Moreover, aspects concerning correct intonation patters and speech rhythm, which are specific for the English language, but do not coincide with the norms of the students' native tongue.

As for the grammatical interference, it can be present during all stages of English learning and be noticeable both in oral and written speech. At primary or initial level, the examples may be the omitting of the article I am (a) pupil, absence of the verb to be in such sentences as $\boldsymbol{M y}$ name (is) Mykola, or leaving out both the article and the verb to be in such a sentence as $\boldsymbol{M y}$ daddy driver. Consequently, grammatical interference can cause incorrect formation of negative verb forms as in My granny not works, wrong word-order in both interrogative sentences What you said?, and affirmative sentences In the article discussed topics, incorrect formation of conditional sentences according to the patterns of the native tongue where the use of future tense verb forms following When and $\boldsymbol{I} \boldsymbol{f}$ is typical, and even formation of plural forms in words that possess such feature in the native language and have no such form in the English language, for example sheeps, moneys, advices, knowledges etc.

Lexical interference often occurs in cases when the word forms coincide in two contrasting languages, but without taking into account the differences in their meaning. Such phenomena are part of the list named "false friends of interpreters" and the examples are as follows actual - topical instead of real, magazine -shop instead of a periodical, critical - satiric instead of significant, roadmap - a road atlas instead of a plan or a guide etc.

Thus, the advocates of the contrastive analysis hypothesis emphasise on the necessity of systemic comparative analysis of languages as a key factor to easy or difficult process of learning English in order to point out similar and different language elements that will help distinguish aspects of more attention and focus. As it has been already mentioned, the contrastive analysis hypothesis aims to predict difficulties in learning a foreign language. According to this goal, the hypothesis continued its development in two directions. One version known today as cross-linguistic influence admits existence and importance of cross-linguistic interference in defining and explaining nascence of difficulties, however at the same time recognising the linguistic difficulties to be more beneficially clarified only afterwards or a posteriori. As students are learning the English language with errors constantly appearing, teachers can employ their knowledge of both the native and target languages to understand the sources of errors and plan their ways of treatment them. Current approach places the emphasis on influence rather than prediction, which is more important. Aside from phonology, which remains the most reliable linguistic category for predicting learner performance, other factors of language present more of a gamble. Syntactic, lexical, and semantic interference demonstrate far more variation among students than psychomotor-based pronunciation interference.

Recent data of cross-linguistic influence have concluded that great difference among languages does not necessarily cause great difficulties. This case highlights the significance of intralingual errors (taking place within one language), which turn out to be as much a factor in English language learning as interlingual errors (across two or more languages). The forms within one language are often perceived to be minimally distinct in comparison to the vast differences between the native and foreign languages, yet those intralingual aspects can lead to some of the greatest difficulties. Today, teachers are recognised to guard against using their previous experience to label students before giving them a chance to perform. Teachers of English at each education level should comprehend the role of cross-linguistic influence as a significant linguistic factor that does not solely demonstrate the effect of influence of one language onto another. Attentive attitude towards lexical and syntactic contrasts across the native tongue and the foreign language can help teachers reduce the number of students' errors in the process of learning English. Any learning process always involves making many kinds of mistakes. They may include miscalculations, false assumptions, mistakes, misjudgements and other kinds, but remain a crucial aspect of a learning process. Learning in all spheres represents a process where success comes as a reward for mistakes made in striving to progress, for mistakes being understood and treated, because mistakes are used to get a teacher's feedback and with that response make new endeavours in achieving desired goals.

English learning is similar to other types of learning, and is built according to the trial-and-error principle. Learners certainly will make mistakes when learning English as they made them while learning their native language. That is why, there exist several types of feedback for students to correct their erroneous learning attempts. Besides, students' mistakes made in the learning a new different language system should be analysed in order for teachers and researchers get further evidence of how languages are learned, what strategies and procedure are used in that process. In order to make a proper analysis of students' language it is crucial to distinguish between mistakes and errors, as they are two diverse phenomena. [1, c. 257] Mistakes can be referred to as performance errors that are either a random guess or a failure to use a known system properly. Mistakes can be selfcorrected if attention is drawn to them. Mistakes must be distinguished from learners' errors that showed a noticeable deviation and reflects the learner's competence. Students who ask 'Does you can swim?', demonstrate a competence level where all English verbs require an auxiliary verb $\boldsymbol{d o}$ in pre-position for question formation. Here it is definitely an error because it reveals the students' 
competence in the English language as the target language.

The fact that students make errors and that the errors can be observed, analysed and classified, has led to the study of students' errors known error analysis. Error analysis can be distinguished from contrastive analysis by its study of errors attributable to a variety of sources, not limited just to negative transfer of the native language. Error analysis easily replaced contrastive analysis because not all errors result from the mother tongue and students with different language background tend to make similar errors while learning the same foreign language. Errors as overt manifestations of students' systems arise from numerous possible sources such as interlingual errors from the native language interference, intralingual errors occurring within the target foreign language, the sociolinguistic context of communication, students' psycholinguistic or cognitive strategies and other multiple affective variables.

In the process of analysis of errors, the first stage is to identify and describe them. In 1971, S. Corder provided a model assisting in identifying errors. [2] The key distinction is made between overt and covert errors. Overt errors are unquestionable ungrammatical at the sentence level. Covert errors are proper formed grammatically but cannot be correctly interpreted in the context of communication. Covert errors cannot be identified without the surrounding discourse. "I'm fine, thanks." sounds absolutely grammatically correct if not to know it is a response to the question "Who are you?», in which case it is obviously incorrect reply.

Besides overt and covert errors, a number of different error categories have been distinguished. [3] The most generalised are errors of adding, omission, substitution, and ordering. The following examples can demonstrate the cases of: adding - Does she be a singer?; a definite article omitting - I went to movie. or I don't play piano.; the wrong word order - We to the store went. or Here a table see we. Moreover, errors can be viewed as global and local. Global errors hinder communication, because they interfere with the listener to comprehend certain aspects of the message. Local errors do not prevent the information from being heard, because it is only a slight violation of one element.

The next stage is to determine the sources of errors. Interlingual transfer is an important source of errors for all students. The initial levels of English learning are especially vulnerable to interlingual transfer from the mother tongue, or interference. In the beginning stages of English learning, much before the new foreign language becomes familiar, students can rely on their native language in their knowledge of a linguistic system. All errors then are because of negative interlingual transfer. While it is not always obvious whether an error is a result of negative interference from the native language, teachers can detect them in their students' speech. Familiarity and even knowledge of a student's native language assist the teacher in noticing and analysing errors.

Intralingual transfer is a characteristic feature within one target foreign language system in language learning, especially when students have acquired certain knowledge of the new language system and began generalising within the target language system. Negative intralingual transfer occurs because of overgeneralisation and can be presented by the following examples:«We goed.»; "I don't know what is it.",etc.

The third significant source of errors, which overlaps both transfer types, is the learning settings. Settings is referred to as either classroom surroundings comprising a teacher, classmates, learning materials etc, or social situation where English learning is taking place. In the context of classroom settings, a teacher or materials can lead to some kinds of false assumptions and provoke induced errors [4]. Students make such errors because of their teacher's misleading explanations, or faulty demonstrated grammatical or lexical structure, and even as a result of rote drilling without proper contextualisation. Phrasal verbs can serve a vivid example as their meaning is far from the meaning of the notional verb in the phase, for example, to look does not mean the same as to look after, to look for and others. Besides these causes, we can mention cases of providing students within correct inappropriate formal language forms that promote learning and consequent using certain old-styled or bookish language instead of currently spoken one.

Attitude towards error treatment whether to ignore or correct errors is still not uniquely defined. Most teachers do not approach learning as a trial-error process and thus emphasise the negative side of making mistakes. This approach tend to focus students' attention on errors and lead to the error fear that cause either negative attitude to English learning or even hinder students' successful learning. However, if a teacher highlights the positive aspects of making errors during learning and sees ways of students' progress in them, it is highly important to consider students' perception of their personal abilities, their tendencies to attribute to teachers' responses and comments, and moreover, the ways students are capable of directing the error influence towards their progress in English learning but not of attributing their failure in learning English.

J. Hendrickson [5] recommended that teachers should distinguish between global and local errors and subsequently treat them differently. She advised teachers not to correct local errors as for the utterances to be understandable. However, the interference into students' speech can break the logical sequence of productive communication. Global errors are viewed as to be unavoidably corrected or otherwise the message will remain unclear and confusing. Moreover, the erroneous linguistic form used once and subsequently not corrected will result in incorporation students' memory and promote fossilisation.

The aspects of how to correct errors are still extremely complex. Besides the fact that students expect their errors to be corrected in classroom settings, some approaches do not advise teachers direct error treatment in the classroom. The explanation is obvious: in non-academic settings, only small percentage of errors made by non-native speakers may be corrected by active native communicators. Sometimes, native speakers show no reaction to the errors, which do not influence communication success. In the mid-1980s, there was suggested a conclusion for a teacher to create a positive and welcoming classroom atmosphere as an optimum environment between the over-polite real-world surroundings and over-corrective expectations students bring with them into the process of learning English. K. Bailey [6] recommended that teach- 
ers should have some basic choices of attitudes toward students' errors namely to work on them or ignore, to treat immediately or later on, to encourageother students to treaterror of their co-learners, and then to examine the treatment efficacy. Actually, these fundamental choice selections continue to be workable options of error treatment nowadays.

As for the error treatment procedure, teachers' feedback types need to be identified. Implicit types of feedback include the following [1]:

1. Recast or giving a new, corrected form is a type of correction that reformulates or expands an incorrect or incomplete message in an unobtrusive way.

2. Request for clarification elicits a correct reformulation or repetition from a learner.

3. Metalinguistic feedback gives comments and questions linked to the correct form of a learner's speech.

4. Elicitation leads students to self- correction.

Explicit forms of feedback comprise a clear demonstration to the learner the incorrectness of the utterance with provision of a correct version of it. Moreover, repetition of an erroneous part of a learner's speech made by a teacher can encourage the learner to reformulate the statement correctly.

Conclusions.To summarise the study conducted, it is necessary to mention that error analysis and treatment, as well as focus on language forms would be more successful if they are a part of a communicative, learner-centred syllabus. Teachers need to develop intuition based on their experience and thorough eclectic knowledge for the most appropriate feedback form to be chosen in a certain communicative or academic situation. That theoretical basis encompasses a combination of behavioural theory covering the principles of reinforcement, theories of human learning, cognitive and socio-cultural factors and aspects of communicative foreign language teaching. Since students learn and acquire a foreign language based on their own intermediate language, that is in-between the students' native language and the target foreign language, teachers are expected to value students' attempts to communication and to give appropriate response for the students to progress in English learning.

Finally, it is significant to state that in order to enhance English learning organisation, it is necessary to remember that presented classifications of errors and mistakes with the existing ways of working them out should be not viewed as prescriptive or overly comprehensive. They aim to assist teachers in improving classroom methodologies and teaching process enhancement as well as to promote students' learning success.

\section{REFERENCES}

1. Brown, H. Douglas(5th ed.) (2007) Principles of language teaching and learning. White Plains, NY: Pearson Education.

2. Corder, S. (1971). Idiosyncratic dialects and error analysis. International Review of Applied Linguistics, 9, 147-159.

3. Lennon, P. (1991). Error: Some problems of definition, identification, and distinction. Appplied Linguistics, 12, 180-196

4. Stenson, N. (1974). Induced errors. In J. Schumann \& N. Stenson (Eds.), New frontiers of second language learning. Rowley, MA: Newbury House.

5. Hendrickson, J. (1980). Error correction in foreign language teaching: Recent theory, research, and practice. In K. Croft (Ed.), Readings on English as a second language ( $2^{\text {nd }}$ ed.). Cambridge, MA: Winthrop.

6. Bailey, K. (1985). Competitiveness and anxiety in adult second language learning: Looking at and through the diary studies. In H. Selinger \& M. Long (Eds.), Classroom oriented research in second language acquisition (pp. 67-102). Rowley, MA: Newbury House. 